Contents list available at Multidisciplinary Journal website

Multidisciplinary Journal

Journal homepage: https://jurnal.unej.ac.id/index.php/multijournal

\title{
Postur Kerja Duduk, Gerakan Berulang, Dan Keluhan Ekstremitas Atas Pada Pekerja Bagian Pelintingan Rokok Cv.Suud Bondowoso
}

\author{
Sitting Work Posture, Repetitive Motions, And Upper Extremity Symptoms For Workers At Manual \\ Cigarettes Rolling Division In CV. Suud Bondowoso \\ Restya Arni Priyanto ${ }^{1}$, Isa Ma'rufi' ${ }^{2}$, Ragil Ismi Hartanti ${ }^{3}$ \\ ${ }^{123}$ Jurusan Ilmu Kesehatan Masyarakat, Fakultas Kesehatan Masyarakat, Universitas Jember Jl. Kalimantan no.37 68121 Jember, Jawa \\ Timur, Indonesia \\ Email: restya.arni.p@gmail.com
}

\begin{abstract}
ABSTRAK. Proses pelintingan rokok di CV.SUUD Bondowoso dilakukan pekerja dengan duduk menunduk bervariasi sesuai postur tubuh pekerja. Meja kerja, kursi kerja, dan alat pelintingan manual yang disediakan oleh pabrik rokok dalam keadaan seragam. Meskipun berukuran seragam akan tetapi perbedaan postur tubuh menyebabkan posisi kerja duduk pekerja beragam. Proses pelintingan rokok di CV.SUUD Bondowoso dilakukan secara berulang-ulang sampai memenuhi target perusahaan. Jenis penelitian yang digunakan dalam penelitian ini adalah penelitian deskriptif. Responden dalam penelitian adalah sebanyak 21 orang pekerja bagian pelintingan rokok CV. SUUD Bondowoso. Variabel yang diteliti pada penelitian ini berupa usia, masa kerja, posisi kerja duduk, gerakan berulang, dan keluhan ekstremitas atas pada pekerja bagian pelintingan rokok CV. SUUD Bondowoso. Hasil penelitian menunjukkan bahwa sebagian besar responden memiliki postur pada level 2. Delapan responden dalam bekerja melakukan gerakan berulang yang termasuk dalam kategori frekuensi tinggi pada bagian tubuh lengan atas, siku, lengan, dan pergelangan tangan. Responden dengan keluhan ekstremitas atas kategori rendah sebanyak 14 orang dan responden dengan keluhan ekstremitas atas kategori sedang yaitu sebanyak 7 orang. Seluruh responden mengalami keluhan pada bagian tubuh leher bawah dan lengan kanan atas.
\end{abstract}

Kata kunci: postur kerja duduk, gerakan berulang, keluhan ekstremitas atas, pelintingan rokok

ABSTRACT. The process of rolling cigarettes in CV. SUUD Bondowoso performed by workers by sitting down in varying manners according to the posture of the worker. Work desks, work chairs, and manual cigarettes rolling equipment are provided by the factory in uniform. Although even though they are similar in size, differences in posture can cause workers' seating positions to vary. The process of rolling cigarettes in CV. SUUD Bondowoso uses repetitive processes to meet the factory's targets. The type of research used in this study is descriptive research. The respondents in the study were 21 workers in the manual cigarettes rolling division of CV. SUUD Bondowoso. The variables examined in this study were age, working period, sitting position, repetitive movements, and upper extremity symptoms for workers workers at manual cigarettes rolling division in CV. SUUD Bondowoso. The results showed that most respondents had posture at level 2. Eight respondents performed repetitive movements at work that fall into the high frequency category on the upper arm, elbow, arm, and wrist. Respondents with low-risk upper extremity symptoms as many as 14 people and respondents with moderate-risk upper extremity symptoms were 7 people. All respondents experienced complaints on the lower neck and right upper arm.

Keywords: sitting work posture, repetitive motions, upper extremity symptoms, cigarettes rolling 


\section{Pendahuluan}

Indonesia dikenal sebagai negara yang menghasilkan tembakau kualitas terbaik di dunia selain Kuba. Ada lebih dari 100 jenis tembakau yang ditanam di Indonesia, lebih dari 250 ribu hektar lahan yang tersebar di Sumatera, Jawa, Bali, dan Lombok. Banyaknya tembakau di Indonesia mendorong perkembangan industri rokok di Indonesia khususnya di Jawa Timur yang menghasilkan rokok jenis kretek maupun filter ditandai dengan adanya sejumlah 291 perusahaan yang terdaftar dalam Kementerian Perindustrian Republik Indonesia (Kemenperin). Kabupaten Bondowoso adalah salah satu kota penghasil tembakau di Jawa Timur selain Madura, Jember, Paiton, Situbondo, Bojonegoro, dan kota lainnya. Salah satu perusahaan industri rokok yang telah berdiri dan bertahan dengan eksistensinya di bidang tembakau adalah CV. SUUD yang beralamat di Desa Sumber Kemuning, Kecamatan Tamanan, Bondowoso. Data dari Dinas Kehutanan dan Perkebunan pada tahun 2016 menunjukkan bahwa CV. SUUD mampu menyerap pembelian tembakau hingga 350 ton dari petani lokal, dengan jenis tembakau kasturi sebanyak 200 ton dan jenis tembakau rajangan sebanyak 150 ton (Arista, 2016:1).

Proses produksi rokok di CV. SUUD Bondowoso dimulai pukul 07.00 sampai pukul 15.00. Proses produksi dilakukan dengan menggunakan mesin yang kemudian menghasilkan rokok filter dan dengan tangan secara manual yang kemudian menghasilkan rokok kretek. Proses produksi rokok kretek di perusahaan dilakukan dengan cara melinting manual dengan menggunakan tangan. Target produksi rokok kretek tersebut adalah 2500 batang per hari. Pada proses pelintingan rokok kretek tersebut meja kerja, kursi kerja, dan alat pelintingan manual yang disediakan oleh pabrik rokok dalam keadaan seragam. Meja kerja yang disediakan oleh pabrik merupakan sebuah meja panjang dimana empat pekerja melakukan pekerjaan di atasnya. Beberapa meja didapati tidak terdapat sandaran kaki sehingga pekerja terkadang menggantung atau menjinjitkan kaki saat melakukan pekerjaan. Pada kursi kerja, pabrik rokok menyediakan kursi berupa kursi kayu dan kursi plastik tanpa sandaran punggung. Beberapa pekerja menambahkan bantalan pada kursi agar terasa lebih nyaman saat bekerja namun beberapa tidak menambahkan bantalan dikarenakan hal tersebut menyebabkan posisi terasa lebih tinggi dari meja kerja yang bisa menyebabkan lebih tidak nyaman. Selain itu, meskipun meja kerja, kursi kerja, dan alat pelintingan rokok manual berukuran seragam akan tetapi perbedaan postur tubuh menyebabkan posisi kerja duduk pekerja beragam. Bagi pekerja yang tinggi atau memiliki berat badan lebih kebanyakan berposisi lebih mennunduk saat bekerja demi ketelitian saat melakukan pekerjaan.

Proses pelintingan rokok menggunakan alat pelintingan manual yang masih tradisional ditambah proses yang dilakukan secara berulang-ulang sampai memenuhi target perusahaan. Target rokok kretek dengan proses pelintingan rokok manual yaitu sebanyak 2500 batang rokok per orang per hari. Contoh gerakan berulang pada proses pelintingan yaitu saat menaruh kertas rokok pada alat linting, mengambil tembakau dan meletakkannya di atas kertas rokok, serta pada saat melinting dan mengecek hasil lintingan rokok. Gerakan monoton dan berulang pada proses pelintingan tersebut dilaksanakan terus-menerus sampai jumlah target terpenuhi. Gerakan berulang yang dilakukan sama secara monoton apabila dilakukan dalam jangka waktu yang lama dan dalam frekuensi yang sering dapat menyebabkan munculnya suatu efek tertentu pada pekerja. Lukas (dalam Rinandha, 2011:13) menyebutkan bahwa upaya perlindungan terhadap bahaya yang timbul serta pencapaian ketentraman atau ketenangan kerja agar pekerja tetap sehat dan selamat bertujuan untuk mencapai produktivitas kerja semaksimal mungkin.

National Research Council and the Institute of Medicine (dalam Feuerstein dkk, 2004:565) menjelaskan bahwa keluhan ekstremitas atas adalah rasa nyeri, kaku, bengkak, dan berkurangnya fungsi tangan, lengan, bahu, dan leher. Pada pekerja yang setiap harinya bekerja dengan posisi kerja duduk dengan gerakan berulang, keluhan tersebut biasanya berupa nyeri di sekitar tengkuk ataupun di bagian bahu. Nyeri dan rasa tidak nyaman pada tengkuk yang biasanya terjadi pada saat bekerja antara lain terjadi pada pekerjaan dengan beban yang berat, pekerjaan manual dengan duduk, serta pekerjaan yang dilakukan dengan duduk terus-menerus. Saat melakukan pekerjaan dengan sikap monoton maka otot bekerja secara statis dimana pembuluh-pembuluh darah dapat tertekan hingga menyebabkan aliran darah dalam otot berkurang dan akhirnya mengakibatkan berkurangnya kadar glukosa serta oksigen dalam darah sehingga harus menggunakan cadangan yang ada (Rinandha, 2011:14).

Keseluruhan proses pelintingan rokok diketahui dilakukan dalam keadaan duduk menggunakan alat linting tradisional. Alat linting berada di atas meja yang memiliki jarak ke mata beragam sesuai postur pekerja sehingga menyebabkan pekerja menunduk dengan sudut berbeda. Kombinasi posisi duduk menunduk dan gerakan monoton berulang ini dilakukan selama waktu kerja jam 7 pagi sampai 15.30 sore pada hari senin sampai minggu kecuali pada hari jumat pada jam 7 pagi sampai jam 15.00 sore, dengan masing-masing jeda istirahat 1 jam per hari. Pekerja biasanya melakukan peregangan kecil disela pekerjaan untuk meminimalisir keluhan lelah, nyeri, dan tidak nyaman selama melinting rokok yang muncul di sekitar tengkuk, bahu, pundak, lengan, dan punggung pada pekerja.

\section{Bahan dan Metode}

Jenis penelitian yang digunakan dalam penelitian ini adalah penelitian deskriptif. Metode deskriptif yaitu metode-metode penelitian yang berpusat kepada masalah atau fenomena yang bersifat aktual pada saat penelitian dilaksanakan, kemudian menggambarkan fakta tentang masalah atau fenomena yang diselidiki sebagaimana adanya diiringi dengan interprestasi yang rasional dan akurat. Penelitian ini dilaksanakan di bagian pelintingan rokok CV. SUUD Desa Sumber Kemuning, Kecamatan Tamanan, Kabupaten Bondowoso. Jumlah sampel penelitian sebanyak 21 
responden yang telah memenuhi kriteria inklusi dan eksklusi dari jumlah populsi pekerja bagian pelintingan di CV. SUUD Bondowoso sebanyak 21 pekerja. Teknik pengambilan sampel penelitian menggunakan teknik sampling jenuh.

Variabel yang diteliti pada penelitian ini berupa usia, masa kerja, posisi kerja duduk, gerakan berulang, dan keluhan ekstremitas atas pada pekerja bagian pelintingan rokok CV. SUUD Bondowoso. Data primer pada penelitian ini diperoleh dari kuesioner yang dilakukan oleh peneliti untuk memperoleh data yang dibutuhkan, yaitu: usia, masa kerja dan keluhan ekstremitas atas. Metode observasi pada penelitian ini berupa pengumpulan data jumlah gerakan berulang dan postur kerja duduk. Proses pelaksaan observasi dilakukan secara non-participation atau tanpa diketahui oleh responden demi menghindari bias atau pengkondisian oleh responden. Teknik analisis data penelitian ini disajikan secara deskriptif. Penyajian data dilakukan melalui tabel distribusi frekuensi dan tabulasi silang (crosstab).

\section{Hasil dan Pembahasan}

Usaha Mikro kecil menengah CV. SUUD Bondowoso berdiri sejak tahun 2016. Perusahaan ini beralamat di Desa Sumber Kemuning, Kecamatan Tamanan, Kabupaten Bondowoso. Pada awalnya perusahaan ini merupakan gudang tembakau saja namun pada akhirnya merambah produksi rokok. Rokok yang diproduksi berupa rokok olahan tangan (SKT) maupun rokok olahan mesin (SKM).

Proses produksi rokok di CV. SUUD Bondowoso dimulai pukul 07.00 sampai pukul 15.00. Proses produksi dilakukan dengan

menggunakan mesin yang kemudian menghasilkan rokok filter dan dengan tangan secara manual yang kemudian menghasilkan rokok kretek. Proses produksi rokok kretek di perusahaan dilakukan dengan cara melinting manual dengan menggunakan tangan. Target produksi rokok kretek tersebut adalah 2500 batang per hari.

Pada proses pelintingan rokok kretek tersebut meja kerja, kursi kerja, dan alat pelintingan manual yang disediakan oleh pabrik rokok dalam keadaan seragam. Meja kerja yang disediakan oleh pabrik merupakan sebuah meja panjang dimana empat pekerja melakukan pekerjaan di atasnya. Beberapa meja didapati tidak terdapat sandaran kaki sehingga pekerja terkadang menggantung atau menjinjitkan kaki saat bekerja. Selain itu pabrik rokok menyediakan kursi berupa kursi kayu dan kursi plastik tanpa sandaran punggung. Beberapa pekerja menambahkan bantalan pada kursi agar terasa lebih nyaman saat bekerja namun beberapa tidak menambahkan bantalan dikarenakan hal tersebut menyebabkan posisi terasa lebih tinggi dari meja kerja yang bisa menyebabkan lebih tidak nyaman.

\section{Karakteristik Responden Usia}

Berdasarkan hasil wawancara dengan menggunakan kuesioner kepada 21 pekerja bagian pelintingan rokok CV. SUUD Bondowoso diperoleh data sebagai berikut:

Tabel 1. Distribusi Responden Berdasarkan Usia

\begin{tabular}{lcc}
\hline \multicolumn{1}{c}{ Usia } & Jumlah & Persentase $(\%)$ \\
\hline 18-24 tahun & 0 & 0 \\
25-34 tahun & 4 & 19 \\
35-44 tahun & 15 & 71,5 \\
45-54 tahun & 2 & 9,5 \\
$>55$ tahun & 0 & 0 \\
\hline Total & 21 & 100 \\
\hline
\end{tabular}

Distribusi sebagian besar usia responden adalah pada rentang usia 35-44 tahun yaitu sebanyak 15 orang (71,5\%).

\section{Masa Kerja}

Berdasarkan hasil wawancara dengan menggunakan kuesioner kepada 21 pekerja bagian pelintingan rokok CV. SUUD Bondowoso diperoleh data sebagai berikut:

Tabel 2. Distribusi Responden Berdasarkan Masa Kerja Usia Frekuensi Persentase (\%)

\begin{tabular}{lcc}
\hline$<2$ Tahun & 1 & 4,8 \\
2-6 Tahun & 20 & 95,2 \\
$>6$ Tahun & 0 & 0
\end{tabular}

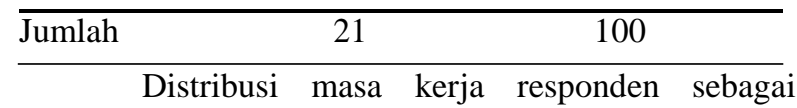
pelinting rokok manual mayoritas adalah pada rentang masa 2-6 tahun yaitu sebanyak 20 orang $(95,2 \%)$.

Postur Kerja Duduk

Berdasarkan hasil observasi dengan menggunakan RULA kepada 21 pekerja bagian pelintingan rokok CV. SUUD Bondowoso diperoleh data sebagai berikut:

Tabel 3 Distribusi Responden Berdasarkan Postur Kerja Duduk

Postur RULA $\quad$ Frekuensi $\quad$ Persentase (\%)

\begin{tabular}{lcc}
\hline Level $1(1-2)$ & 0 & 0 \\
Level $2(3-4)$ & 15 & 71,5 \\
Level $3(5-6)$ & 6 & 28,5 \\
Level $4(7-7+)$ & 0 & 0
\end{tabular}

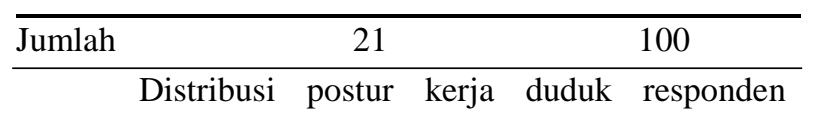
sebagai pelinting rokok manual sebagian besar adalah pada level 2 yaitu sebanyak 15 orang $(71,5 \%)$. Level 2 adalah saat penyelidikan lebih lanjut dibutuhkan dan mungkin saja membutuhkan perubahan pada postur pekerja.

\section{Gerakan Berulang}

Berdasarkan hasil observasi kepada 21 pekerja bagian pelintingan rokok CV. SUUD Bondowoso diperoleh data sebagai berikut: 
Citation: Restya Arni Priyanto, Isa Ma'rufi, Ragil Ismi Hartanti. (2021), Postur Kerja Duduk, Gerakan Berulang, Dan Keluhan

Tabel 4. Distribusi Responden Berdasarkan Gerakan Berulang

\begin{tabular}{|c|c|c|c|c|}
\hline \multirow[t]{2}{*}{$\begin{array}{l}\text { Anggota } \\
\text { Tubuh }\end{array}$} & \multicolumn{4}{|c|}{$\begin{array}{l}\text { Gerakan } \\
\text { Berulang }\end{array}$} \\
\hline & \multicolumn{4}{|c|}{ RendahPersenta Tinggi Persenta } \\
\hline Bahu & 21 & 100 & 0 & 0 \\
\hline Lengan Atas & & 38,1 & 13 & 61,9 \\
\hline Siku & 8 & 38,1 & 13 & 61,9 \\
\hline Lengan & 8 & 38,1 & 13 & 61,9 \\
\hline $\begin{array}{l}\text { Pergelangan } \\
\text { Tangan }\end{array}$ & & 38,1 & 13 & 61,9 \\
\hline Jari & 21 & 100 & 0 & 0 \\
\hline
\end{tabular}

Sebagian besar responden melakukan gerakan berulang dalam frekuensi tinggi pada bagian tubuh lengan atas, siku, lengan, dan pergelangan tangan yaitu sebanyak 13 orang $(61,9 \%)$.

\section{Keluhan Ekstremitas Atas}

Berdasarkan hasil perhitungan dari kuesioner Nordic Body Map kepada 21 pekerja bagian pelintingan rokok CV. SUUD Bondowoso diperoleh data sebagai berikut:

Tabel 5 Distribusi Responden Berdasarkan Hasil Nordic Body Map

\begin{tabular}{lcc}
\hline $\begin{array}{l}\text { Keluhan } \\
\text { Ekstremitas Atas }\end{array}$ & Intensitas & $\begin{array}{c}\text { Persentase } \\
(\%)\end{array}$ \\
\hline Rendah & 14 & 66,7 \\
Sedang & 7 & 33,3 \\
Tinggi & 0 & 0 \\
Sangat Tinggi & 0 & 0 \\
\hline Jumlah & 18 & 100
\end{tabular}

Sebagian besar responden dengan keluhan ekstremitas atas kategori rendah yaitu sebanyak 14 orang $(66,7 \%)$. Berdasarkan kuesioner Nordic Body Map diperoleh kelompok usia 3544 tahun adalah kelompok yang sebagian besar mengalami keluhan ekstremitas atas dengan lebih dari separuh responden pada kelompok usia tersebut masih mengalami keluhan ekstremitas atas kategori rendah. juga data keluhan rasa tidak nyaman, kaku, dan nyeri yang dirasakan responden serta keparahan keluhankeluhan tersebut. Lokasi keluhan dirinci berdasarkan anggota tubuh yang termasuk anggota tubuh ekstremitas atas. Keluhan terbagi dalam 4 kategori yaitu tidak ada keluhan (1), tidak nyaman atau kaku atau kesemutan (2), nyeri (3), dan sangat nyeri (4). Distribusi keluhan dan keparahan yang dialami 21 responden bisa dilihat dalam tabel berikut:

Tabel 6. Distribusi Keluhan dan Keparahan pada Anggota Tubuh Ekstremitas Atas

\begin{tabular}{lcccccc}
\hline Lokasi Nyeri & \multicolumn{2}{l}{$\begin{array}{l}\text { Keluhan } \\
\text { Responden }\end{array}$} & \multicolumn{3}{l}{ Sebaran Keluhan } \\
\cline { 2 - 7 } & $\mathrm{n}$ & $\%$ & $\mathrm{n}$ & $\%$ & $\mathrm{n}$ & $\%$ \\
\hline Leher Atas & 17 & 80,9 & 7 & 41,2 & 10 & 58,8 \\
Leher Bawah & 21 & 100 & 3 & 14,3 & 18 & 85,7
\end{tabular}

\begin{tabular}{lcccccc} 
Pundak kiri & 20 & 95,2 & 9 & 45 & 11 & 55 \\
Pundak & 20 & 95,2 & 9 & 45 & 11 & 55 \\
$\begin{array}{l}\text { Kanan } \\
\text { Lengan Atas }\end{array}$ & 8 & 38,1 & 8 & 100 & 0 & 0 \\
$\begin{array}{l}\text { Kiri } \\
\text { Punggung }\end{array}$ & 7 & 33,3 & 7 & 100 & 0 & 0 \\
$\begin{array}{l}\text { Lengan Atas } \\
\text { Kanan }\end{array}$ & 21 & 100 & 7 & 33,3 & 14 & 66,7 \\
Pinggang & 14 & 66,7 & 8 & 57,2 & 6 & 42,8 \\
Pinggul & 17 & 80,9 & 4 & 23,6 & 13 & 76,4 \\
$\begin{array}{l}\text { Pantat } \\
\text { Lengan kiri }\end{array}$ & 14 & 66,7 & 11 & 78,6 & 3 & 21,4 \\
$\begin{array}{l}\text { Lengan kanan } \\
\text { Pergelangan }\end{array}$ & 17 & 80,9 & 2 & 11,8 & 15 & 88,2 \\
tangan kiri & 71,4 & 13 & 86,7 & 2 & 13,3 \\
$\begin{array}{l}\text { Pergelangan } \\
\text { tangan kanan }\end{array}$ & 15 & 71,4 & 13 & 86,7 & 2 & 13,3 \\
\hline
\end{tabular}

Keluhan yang dialami oleh semua responden (100\%) adalah pada bagian tubuh leher bawah dan lengan kanan atas. Pundak kiri dan pundak kanan adalah bagian tubuh selanjutnya yang mayoritas dikeluhkan oleh responden yaitu sebanyak 20 orang $(95,2 \%)$ disusul dengan leher atas dan pinggul yang mayoritas juga dikeluhkan oleh responden yaitu sebanyak 17 orang $(80,9 \%)$

\section{Keluhan Ekstremitas Atas dengan Usia}

Hasil analisis tabulasi silang usia dengan keluhan ekstremitas atas kepada 21 pekerja bagian pelintingan rokok CV. SUUD Bondowoso secara lengkap dapat dilihat pada Tabel 7.

Tabel 7. Distribusi Frekuensi Usia dengan Keluhan Ekstremitas Atas

\begin{tabular}{|c|c|c|c|c|c|c|}
\hline \multirow{4}{*}{ Usia } & \multicolumn{5}{|c|}{ Keluhan Ekstremitas } & \multirow{4}{*}{$\begin{array}{l}\text { Persentas } \\
\text { e }(\%)\end{array}$} \\
\hline & & Ata & & & Total & \\
\hline & \multicolumn{2}{|c|}{ Rendah } & \multicolumn{2}{|c|}{ Sedang } & & \\
\hline & $\mathrm{n}$ & $\%$ & $\mathrm{n}$ & $\%$ & & \\
\hline $\begin{array}{l}25-34 \\
\text { Tahun }\end{array}$ & 2 & 9,5 & 2 & 9,5 & 4 & 19 \\
\hline $\begin{array}{l}35-44 \\
\text { Tahun }\end{array}$ & 11 & 52,4 & 4 & 19 & 15 & 71,4 \\
\hline $\begin{array}{l}45-54 \\
\text { Tahun } \\
\end{array}$ & 1 & 4,8 & 1 & 4,8 & 2 & 9,6 \\
\hline
\end{tabular}


Keluhan Ekstremitas Atas dengan Masa Kerja

Hasil analisis tabulasi silang masa kerja dengan keluhan ekstremitas atas kepada 21 pekerja bagian pelintingan rokok CV. SUUD Bondowoso secara lengkap dapat dilihat pada Tabel 8.

Tabel 8. Distribusi Frekuensi Masa Kerja dengan Keluhan Ekstremitas Atas

Keluhan Ekstremitas

Persentase

Atas

Total

\begin{tabular}{|c|c|c|c|c|c|c|}
\hline \multirow{2}{*}{$\begin{array}{l}\text { Masa } \\
\text { Kerja }\end{array}$} & \multicolumn{2}{|c|}{ Rendah } & \multicolumn{2}{|c|}{ Sedang } & & \\
\hline & $\mathrm{n}$ & $\%$ & $\mathrm{n}$ & $\%$ & & \\
\hline$<2$ Tahun & 1 & 4,8 & 0 & $\overline{0}$ & 1 & 4,8 \\
\hline 2-6 Tahun & 13 & 61,9 & 7 & 33,3 & 20 & 95,2 \\
\hline
\end{tabular}

Hasil dalam tabulasi silang pada Tabel 1.8

menunjkkan bahwa satu-satunya responden pada rentang masa kerja 2-6 tahun sebagian besar memiliki keluhan ekstremitas atas kategori rendah yaitu sebanyak 13 responden dengan persentase $61,9 \%$ dan kategori sedang yaitu sebanyak 7 responden dengan persentase $33,3 \%$.

\section{Keluhan Ekstremitas Atas dengan Postur Kerja} Duduk

Hasil analisis tabulasi silang postur kerja dengan keluhan ekstremitas atas kepada 21 pekerja bagian pelintingan rokok CV. SUUD Bondowoso secara lengkap dapat dilihat pada Tabel 1.9.

Tabel 9. Distribusi Frekuensi Postur Kerja dengan Keluhan Ekstremitas Atas

$$
\text { Keluhan Ekstremitas }
$$

\begin{tabular}{|c|c|c|c|c|c|c|}
\hline \multirow{4}{*}{$\begin{array}{l}\text { Postur } \\
\text { Kerja }\end{array}$} & \multicolumn{4}{|c|}{ Keluhan Ekstremitas } & \multirow{4}{*}{ Total } & \multirow{3}{*}{$\begin{array}{l}\text { ersentas } \\
\qquad(\%)\end{array}$} \\
\hline & \multicolumn{4}{|c|}{ Atas } & & \\
\hline & \multicolumn{2}{|c|}{ Rendah } & \multicolumn{2}{|c|}{ Sedang } & & \\
\hline & $\mathrm{n}$ & $\%$ & $\mathrm{n}$ & $\%$ & & \\
\hline Level 2 & 12 & $\overline{57,2}$ & 2 & 9,5 & 14 & 66,7 \\
\hline Level 3 & 3 & 14,3 & 4 & 19 & 7 & 33,3 \\
\hline
\end{tabular}

Hasil dalam tabulasi silang pada Tabel 1.9 menunjukkan bahwa kelompok responden pada level 2 memiliki keluhan ekstremitas atas kategori rendah yaitu sebanyak 12 orang $(57,2 \%)$ dan kategori sedang yaitu sebanyak 2 orang $(9,5 \%)$. Level 2 berarti bahwa penyelidikan lebih lanjut dibutuhkan dan mungkin saja membutuhkan perubahan pada postur kerja responden tersebut. Kelompok responden pada level 3 memiliki keluhan ekstremitas atas kategori rendah yaitu sebanyak 3 orang $(14,3 \%)$ dan kategori sedang yaitu sebanyak 4 orang (19\%). Level 3 berarti bahwa penyelidikan dan perubahan pada postur kerja responden harus dilakukan segera.

\section{Keluhan Ekstremitas Atas dengan Gerakan Berulang}

Hasil analisis tabulasi silang gerakan berulang dengan keluhan ekstremitas atas kepada 21 pekerja bagian pelintingan rokok CV. SUUD Bondowoso secara lengkap dapat dilihat pada Tabel 10.

Tabel 10. Distribusi Frekuensi Gerakan Berulang dengan Keluhan Ekstremitas Atas

\begin{tabular}{|c|c|c|c|c|c|}
\hline \multirow{3}{*}{$\begin{array}{c}\text { Gerakan } \\
\text { Berulang } \\
\text { Frekuensi Tinggi } \\
\end{array}$} & \multicolumn{4}{|c|}{ Keluhan Ekstremitas } & \multirow[t]{3}{*}{ Total } \\
\hline & \multicolumn{2}{|c|}{ Rendah } & \multicolumn{2}{|c|}{ Sedang } & \\
\hline & $\mathrm{n}$ & $\%$ & $\mathrm{n}$ & $\%$ & \\
\hline Lengan Atas & 5 & 62,5 & 3 & 37,5 & 13 \\
\hline Siku & 5 & 62,5 & 3 & 37,5 & 13 \\
\hline Lengan & 5 & 62,5 & 3 & 37,5 & 13 \\
\hline $\begin{array}{l}\text { Pergelangan } \\
\text { Tangan }\end{array}$ & 5 & 62,5 & 3 & 37,5 & 13 \\
\hline
\end{tabular}

Hasil dalam tabulasi silang pada Tabel 1.10 menunjukkan 8 responden yang melakukan pekerjaan dengan gerakan berulang frekuensi tinggi pada anggota tubuh lengan atas, siku, lengan, dan pergelangan tangan. Delapan responden tersebut memiliki keluhan ekstremitas atas kategori rendah sebanyak 5 orang $(62,5 \%)$ dan kategori sedang sebayak 3 orang $(37,5 \%)$.

\section{Pembahasan}

Usia

distribusi sebagian besar usia responden adalah pada rentang usia 35-44 tahun yaitu sebanyak 15 orang $(71,5 \%)$, kemudian dilanjutkan oleh responden dengan rentang usia 25-34 tahun yaitu sebanyak 4 orang (19\%), dan responden dengan rentang usia 45-54 tahun yaitu sebanyak 2 orang $(9,5 \%)$. Menurut Rusdi (dalam Rinandha, 2011:34) dengan bertambahnya usia dapat dipastikan bahwa paparan dengan alat kerja tangan makin lama pula karena penggunaan tiap hari pada waktu kerja dan kemampuan elastisitas tulang, otot, ataupun urat semakin berkurang sebagai peredam dari getaran yang dirambatkan ke tubuh.

Masa Kerja

Postur kerja yang statis dengan masa kerja yang lama (2 - 6 tahun bekerja) menurut Yuli (dalam Ningrum, 2016:24) dapat berpengaruh terhadap keluhan muskuloskeletal. Menurut Harrianto (dalam Ningrum, 2016:24), keluhan muskuloskeletal tersebut disebabkan karena adanya akumulasi pembebanan pada tulang rangka. Berdasarkan hasil wawancara dengan menggunakan kuesioner kepada 21 pekerja bagian pelintingan rokok CV. SUUD Bondowoso diketahui bahwa distribusi masa kerja responden sebagai pelinting rokok manual mayoritas berada pada rentang masa 2-6 tahun yaitu sebanyak 20 orang $(95,2 \%)$, kemudian sisanya adalah 1 orang $(4,8 \%)$ responden dengan masa kerja di bawah 2 tahun. 


\section{Postur Kerja Duduk}

Postur kerja duduk responden pada penelitian ini didapatkan dari hasil observasi dengan menggunakan RULA kepada 21 pekerja bagian pelintingan rokok CV. SUUD. Hasil penelitian menunjukkan bahwa distribusi postur kerja duduk responden sebagai pelinting rokok manual paling banyak adalah pada level 2 yaitu sebanyak 15 orang $(71,5 \%)$, kemudian sisanya adalah responden dengan level 3 yaitu sebanyak 6 orang (28,5\%). Responden yang memiliki postur kerja level 2 adalah seluruh responden yang mendapatkan skor 3 dan 4 pada hasil perhitungan grand score setelah observasi menggunakan RULA. Level 2 yang diperoleh 15 responden $(71,5 \%)$ menunjukkan bahwa postur kerja dari 15 responden tersebut membutuhkan penyelidikan lebih lanjut dan mungkin saja membutuhkan perubahan. Sedangkan responden yang memiliki postur kerja level 3 adalah seluruh responden yang mendapatkan skor 5 dan 6 pada hasil perhitungan grand score setelah observasi menggunakan RULA. Level 3 yang diperoleh 6 responden (28,5\%) menunjukkan bahwa postur kerja dari 6 responden tersebut membutuhkan penyelidikan lebih lanjut dan harus segera melakukan perubahan.

\section{Gerakan Berulang}

Setiap anggota tubuh berbeda memiliki acuan tersendiri dalam hitungan risiko pengulangan. Kilbom (2000:149) merinci dari berbagai sumber tentang jumlah gerakan minimal yang harus dilakukan suatu bagian tubuh untuk

dikategorikan memiliki risiko tinggi. Rincian tersebut berupa jumlah minimal pengulangan pergerakan bahu yang diperoleh dari penelitian Winkel dan Westgaard (1992), pada lengan atas dan siku diperoleh dari penelitian Dul dkk. (1991), lengan dan pergelangan tangan diperoleh dari penelitian Bystrom (1991), serta pengulangan gerakan jari diperoleh dari penelitian Ferguson (1971).

Pengulangan pergerakan pada anggota tubuh dihitung sebanyak jumlah gerakan yang diulang pada tiap pengukuran dengan asumsi semakin banyak pengulangan gerakan yang dilakukan maka frekuensi pengulangan gerakan dikatakan sebagai pengulangan frekuensi tinggi. Hasil penelitian menunjukkan bahwa responden yang melakukan gerakan berulang dalam frekuensi tinggi pada bagian tubuh lengan atas, siku, lengan, dan pergelangan tangan adalah sebanyak 8 orang $(38,1 \%)$.

\section{Keluhan Ekstremitas Atas}

National Research Council and the Institute of Medicine (dalam Feuerstein dkk,

2004:565) menjelaskan bahwa keluhan ekstremitas atas adalah rasa nyeri, kaku, bengkak, dan berkurangnya fungsi tangan, lengan, bahu, dan leher. Data keluhan ekstremitas atas dalam

kerja tinggi, dukungan sosial rendah, kontrol pekerjaan rendah, dan tekanan batas waktu), dan faktor risiko individual (jenis kelamin, usia, waktu istirahat yang penelitian ini diperoleh dari hasil perhitungan dari kuesioner Nordic Body Map kepada 21 pekerja bagian pelintingan rokok CV. SUUD Bondowoso. Hasil penelitian menunjukkan bahwa responden dengan keluhan ekstremitas atas kategori rendah sebanyak 14 orang $(66,7 \%)$ dan responden dengan keluhan ekstremitas atas kategori sedang yaitu sebanyak 7 orang $(33,3 \%)$.

Selain itu, berdasarkan kuesioner Nordic Body Map diperoleh juga data keluhan rasa tidak nyaman, kaku, dan nyeri yang dirasakan responden serta keparahan keluhan-keluhan tersebut. Lokasi keluhan dirinci berdasarkan anggota tubuh yang termasuk anggota tubuh ekstremitas atas. Keluhan terbagi dalam 4 kategori yaitu tidak ada keluhan (1), tidak nyaman atau kaku atau kesemutan (2), nyeri (3), dan sangat nyeri(4). Hasil penelitian menunjukkan bahwa keluhan terbanyak yang dialami oleh responden terdapat pada bagian tubuh leher bawah dan lengan kanan atas yaitu dialami oleh 21 orang (100\%). Pada bagian tubuh leher bawah, responden yang merasakan nyeri sebanyak 18 orang $(85,7 \%)$ sedangkan responden yang sekedar merasakan keluhan tidak nyaman, kaku, atau kesemutan adalah sebanyak 3 orang $(41,2 \%)$. Pada bagian tubuh lengan atas kanan, sebanyak 14 orang $(66,7 \%)$ merasakan nyeri dan 7 orang lainnya

$(33,3 \%)$ sekedar merasakan keluhan tidak nyaman, kaku, atau kesemutan. Pundak kiri dan pundak kanan adalah bagian tubuh selanjutnya yang banyak dikeluhkan oleh responden yaitu sebanyak 20 orang $(95,2 \%)$ dengan rincian masing-masing sebanyak 11 orang $(55 \%)$ merasakan nyeri dan 9 orang $(45 \%)$ sekedar merasakan keluhan tidak nyaman, kaku, atau kesemutan.

Keluhan pada leher atas, pinggul, lengan kanan dialami oleh 17 orang $(80,9 \%)$. Keluhan pada lengan kiri, pergelangan tangan kiri, dan pergelangan tangan kanan masing-masing dialami oleh 15 orang $(71,4 \%)$. Keluhan pada pinggang dan pantat dialami oleh 14 orang $(66,7 \%)$. Keluhan pada punggung dialami oleh 8 orang $(38,1 \%)$. Keluhan pada lengan atas kiri dialami oleh 7 orang $(33,3 \%)$.

\section{Keluhan Ekstremitas Atas dengan Usia}

Pada penelitian ini diketahui bahwa usia sebagian besar responden berada pada kisaran 35 sampai 44 tahun. Namun dalam hal keluhan ekstremitas atas, seluruh responden dari berbagai rentang usia menyatakan bahwa ada keluhan ekstremitas atas yang dirasakan baik rendah maupun sedang. Hal ini sejalan dengan uraian dari Feuerstein, dkk (2004:566) bahwa keluhan ekstremitas atas akibat kerja muncul akibat tiga

kategori faktor risiko yang muncul berkesinambungan yaitu kategori pajanan biomekanik (gerakan berulang, high force, postur janggal), stresor psikososial (level stres tempat

kurang memuaskan, dan tambahan beban pekerjaan luar).

Keluhan Ekstremitas Atas dengan Masa Kerja 
Hasil penelitian pada CV.SUUD Bondowoso menunjukkan adanya keluhan ekstremitas atas yang dirasakan seluruh responden dalam berbagai intensitas keluhan. Namun masa kerja yang hampir homogen yaitu 20 dari 21 responden yang bekerja dalam rentang masa kerja yang sama menjadikan informasi mengenai keterkaitan masa kerja dengan munculnya keluhan ekstremitas atas pada responden di CV. SUUD Bondowoso masih belum bisa dipastikan. Pada penelitian lain oleh Hamida (2015) disebutkan bahwa tidak ada hubungan signifikan antara masa kerja dan keluhan ekstremitas atas. Turut dijelaskan pula bahwa tidak adanya hubungan signifikan antara masa kerja dengan keluhan ekstremitas atas tersebut disebabkan adanya proses adaptasi oleh tubuh. Proses adaptasi tersebut memberikan efek positif yaitu dapat menurunkan ketegangan dan meningkatkan performa kerja.

\section{Keluhan Ekstremitas Atas dengan Postur Kerja Duduk}

Pada penelitian ini dapat disimpulkan bahwa kelompok responden yang memiliki keluhan ekstremitas atas kategori rendah adalah sebanyak 15 orang, sedangkan responden yang memiliki keluhan ekstremitas atas kategori sedang adalah sebanyak 6 orang. Penelitian serupa oleh Hamida (2015) menunjukkan bahwa seluruh tenaga kerja termasuk kategori resiko rendah tetapi semua tenaga kerja bagian pelintingan mengalami nyeri pada bagian tubuh atas. Penelitian lain oleh Rinandha (2011) menunjukkan adanya hubungan yang signifikan antara postur kerja duduk dengan Upper Extremity Symptoms pada pekerja bagian cucuk di PT. Iskandartex Surakarta. Penelitian yang dilakukan oleh Tana (2009) turut menjelaskan menjelaskan bahwa responden yang bekerja dengan posisi lebih banyak duduk memiliki 1,4 kali kecenderungan resiko dibanding dengan posisi kerja lebih banyak berdiri. Hal ini diperparah ketika responden selama jam kerja duduk pada bangku kerja yang tidak memiliki sandaran untuk punggung dan lengan. Ariens, dkk (dalam Tana, 2009: 20) menyebutkan bahwa ada hubungan yang positif pada posisi duduk lebih dari $95 \%$ jam kerja dengan nyeri leher. Ariens, dkk (dalam Tana, 2009: 20) pada penelitian lainnya juga melaporkan adanya hubungan antara keluhan nyeri leher dan ekstremitas atas dengan posisi leher menunduk saat bekerja.

\section{Keluhan Ekstremitas Atas dengan Gerakan Berulang}

Hasil penelitian pada pekerja proses pelintingan rokok CV. SUUD Bondowoso menunjukkan bahwa 8 responden yang melakukan pekerjaan dengan gerakan berulang frekuensi tinggi pada anggota tubuh lengan atas, siku, lengan, dan pergelangan tangan. Rincian dari 8 responden tersebut adalah sebanyak 5 orang $(62,5 \%)$ memiliki keluhan ekstremitas atas dengan kategori sedang dan sebayak 3 orang $(37,5 \%)$ memiliki keluhan ekstremitas atas dengan kategori rendah.

Penelitian serupa oleh Hamida (2015) menunjukkan terdapat hubungan yang sangat signifikan antara repetitive motion dengan keluhan muskuloskeletal ekstremitas atas pada pekerja pelintingan PT. Djitoe Indonesian Tobacco. Hasil pada penelitian tersebut menunjukkan nilai kekuatan hubungan antar variabel sebesar 0,362 yang berarti kekuatan korelasinya lemah. Untuk nilai koefisien determinan sebesar $13,1 \%$ yang berarti sumbangan repetitive motion terhadap keluhan muskuloskeletal ekstremitas atas yaitu sebesar $13,1 \%$ sedangkan sisanya $86,9 \%$ dipengaruhi oleh faktor lain. Penelitian lain yang dilakukan oleh Tana (dalam Nuraini, 2016:45) menyebutkan bahwa $79 \%$ dari 658 penderita carpal tunnel syndrome bekerja dengan gerakan biomekanik berulang.

\section{Kesimpulan}

Sebagian besar usia responden adalah pada rentang usia 35-44 tahun yaitu sebanyak 15 orang $(71,5 \%)$ sedangkan distribusi masa kerja responden mayoritas berada pada rentang masa 2-6 tahun yaitu sebanyak 20 orang $(95,2 \%)$. Postur kerja duduk responden sebagai pelinting rokok manual paling banyak adalah pada level 2 yaitu sebanyak 15 orang $(71,5 \%)$ dimana hal tersebut menunjukkan bahwa postur kerja dari 15 responden tersebut membutuhkan penyelidikan lebih lanjut dan mungkin saja membutuhkan perubahan. Responden yang melakukan gerakan berulang dalam frekuensi tinggi pada bagian tubuh lengan atas, siku, lengan, dan pergelangan tangan adalah sebanyak 8 orang responden $(38,1 \%)$. Seluruh responden mengalami keluhan pada bagian tubuh leher bawah dan lengan kanan. Pundak kiri dan pundak kanan adalah bagian tubuh selanjutnya yang dikeluhkan oleh mayoritas responden. Pada responden kelompok usia 35-44 tahun, terdapat 11 orang $(52,4 \%)$ mengalami keluhan ekstremitas atas kategori rendah. Responden yang memiliki keluhan ekstremitas atas kategori rendah yaitu dengan rincian responden yang memiliki postur level 2 sebanyak 12 orang dan level 3 sebanyak 3 orang. Sedangkan responden yang memiliki keluhan ekstremitas atas kategori sedang yaitu dengan rincian responden yang memiliki postur level 2 sebanyak 2 orang dan level 3 sebanyak 4 orang. Delapan responden diketahui melakukan pekerjaan dengan gerakan berulang frekuensi 
tinggi dengan rincian 5 orang memiliki keluhan ekstremitas atas kategori rendah dan 3 orang memiliki keluhan ekstremitas atas kategori sedang.

\section{Referensi}

Arista, Diana. APTI Menilai Pemkab

bondowoso

Belum Berpihak Kepada Petani Tembakau.http://rri.co.id/jember/post/berita/269454/ekonomi/apt _menilaipemkab_bondowoso_belum_berpihak_kepada_petani_te mbakau.html Diakses pada 20Desember 2019

Feuerstein, Michael dkk. 2004. Job Stress Management and Ergonomic Intervention for Work-Related Upper Extremity Symptomps. Jurnal ilmiah Elsevier Applied Ergonomics 35 Mei 2004 hlm 565-574.

Hamida, M. Fajar. 2015. Hubungan Repetitive Motion dengan Keluhan Muskuloskeletal Ekstrimitas Atas pada Pekerja Pelintingan PT. Djitoe Indonesian Tobaco. Skripsi.Surakarta: Universitas Sebelas Maret.

Kementerian Perindustrian Republik Indonesia. Daftar Perusahaan Rokok. http://kemenperin.go.id/direktoriperusahaan what=rokok \&prov=35\&hal $=6$ Diakses pada 20 Agustus 2019

Kilbom, Asa. 2000. Repetitive Works of the Upper Extremity: part IGuidelines for Practitioner. Jurnal Elsevier Ergonomics Books volume 1. Hal 145-150
Kilbom, Asa. 2000. Repetitive Works of the Upper Extremity: part II-The Scientific Basis (Knowledge Base) for the Guide. Jurnal Elsevier Ergonomics Books volume 1 Hal 151-178

Ningrum, Fani Fatimah Kusuma. 2016. Hubungan postur kerja duduk dan gerakan berulang dengan keluhan cumulative trauma disorder (CTD) pada penjahit di CV. Maju Abadi Garment Sukoharjo. Skripsi. Surakarta: Universitas Sebelas Maret

Nuraini, Tiara. 2016. Hubungan Gerakan Berulang pada Tangan dengan Keluhan Carpal Tunnel Syndrome pada Pekerja Penjilid Buku di PT. Putra Nugraha Triyagan, Sukoharjo. Skripsi. Surakarta: Universitas Sebelas Maret.

Prabowo, Yusuf Milan. 2016. Hubungan Postur Kerja Duduk dan Gerakan Berulang dengan Keluhan Muskuloskeletal Tenaga Kerja Sewing Garmen CV. SAA Sukoharjo. Skripsi. Surakarta: Universitas Sebelas Maret.

Rinandha, Cherlly Pritta. 2011. Hubungan Postur Kerja Duduk terhadap Upper Extremity Symptomps pada Pekerja Bagian Cucuk di PT. Iskandartex Surakarta. Skripsi. Surakarta: Universitas Sebelas Maret.

Susila dan Suyanto. 2015. Metodologi Penelitian Cross Sectional. Klaten: Bossscript.

Tana, Lusianawaty dkk. 2009. Hubungan lama kerja dan posisi kerja dengan keluhan leher dan ekstremitas atas pada pekerja garmen perempuan di jakarta utara. Jurnal Bul.Penel. Kesehatan vol. 37 no. 12009 12-22. 